\title{
Effects of EOR chemicals and superficial gas velocity on bubble size and gas holdup of a bubble column
}

\author{
Aloisio E. Orlando Jr. ${ }^{1,3, *}$, Luiz F. Barca ${ }^{2}$, Tania S. Klein ${ }^{3}$, and Ricardo A. Medronho ${ }^{3}$ \\ ${ }^{1}$ Department of Technologies for Water Treatment and Reuse, PETROBRAS Research Center, 21941-915 Rio de Janeiro, Brazil \\ ${ }^{2}$ Federal University of Itajubá, Institute of Mechanical Engineering, Compact Separators Center, 37500-903 Itajubá, Brazil \\ ${ }^{3}$ Department of Chemical Engineering, Federal University of Rio de Janeiro, School of Chemistry, 21941-909 Rio de Janeiro, Brazil
}

Received: 26 March 2019 / Accepted: 11 October 2019

\begin{abstract}
Chemical Enhanced Oil Recovery (EOR) can boost oil extraction in offshore operations, however one of the main concerns regarding its application is how the efficiency of flotation units for treating produced water is affected. The present work thus focuses on investigating the impact of EOR chemicals on the physical properties of EOR effluents and how this can affect flotation performance parameters such as bubble size and gas holdup. Design of experiments has been used to assess the influence of polymer, surfactant and sodium chloride concentrations on bubble size and gas holdup of a laboratorial bubble column. The influence of superficial gas velocity has also been assessed together with chemicals concentrations, yet at low levels in order to avoid clusters, swarms and foam. The characterization of the synthetic effluent containing polymer, surfactant and sodium chloride has indicated that the fluid behaves as a non-Newtonian fluid, what makes separation processes in flotation cells challenging. Results showed that polymer concentration of $2000 \mathrm{mg} / \mathrm{L}$ can lead to significant increases in fluid viscosity, promote a growth of more than $40 \%$ in bubble size and only increases gas holdup when surfactant is present at high concentration. Therefore, polymers are expected to be detrimental to produced water treatment. Surfactants decrease both fluid surface tension and bubble size, increasing gas holdup. For the range studied, superficial gas velocity favors gas holdup and sodium chloride concentration seems to weakly influence bubble size and gas holdup. This work highlights the fact that changes in physical properties of produced water do modify bubble size distribution and gas holdup and this must therefore be taken into account when flotation-like systems are designed to deal with EOR effluents.
\end{abstract}

\section{Introduction}

Enhanced Oil Recovery (EOR) encompasses several methods for increasing the production of petroleum reservoirs [1]. According to Thomas [2], EOR methods consist of chemical, electrical, miscible, steam and thermal techniques. These methods have proven to boost oil recovery from mature reservoirs when conventional methods (water flooding) no longer work [3]. Chemical enhanced oil recovery comprehends water injection with different additives to enhance the removal of oil from the reservoir. Among the chemical methods, the main techniques are polymer flooding and Surfactant/Polymer (SP) flooding [4].

Polymer flooding mechanism operates by decreasing the mobility of the water phase, reducing the incidence of fingering effects [5]. Besides, polymers are responsible for increasing the viscosity of the water and, therefore, improving the efficiency of oil sweeping [6].

\footnotetext{
* Corresponding author: aloisio.orlando@petrobras.com.br
}

Surfactants have the function of reducing the interfacial tension between water and oil phases, enhancing the mobility of the oil, as well as modifying the wettability of the porous rock [7]. The combined injection of surfactants and polymers into the reservoir (SP flooding) may increase sweep efficiency [8].

Due to this ability to improve the oil/water mobility ratio, in the past few years, chemical methods for EOR have been implemented at various onshore sites [9]. Ma et al. [10] reported the success of the polymer flooding technique that enhanced oil recovery by more than $12 \%$ in the oil industry.

Such results suggest that applying chemical EOR methods in the offshore environment would increase oil recovery. On the other hand, some researchers point out obstacles to the effective use of EOR methods in offshore oilfields. One such restriction is the inability of available technologies to process the produced water containing EOR [11-13].

The produced water system in offshore installations is usually equipped with skim tanks, gas flotation/degassers and hydrocyclones [14]. In the case of EOR effluents, 
Wang et al. [15] reported that the use of hydrocyclones was an inefficient method for treating the water produced by polymer flooding.

Although Chen et al. [16] confirm the benefits of the polymer flooding in offshore operations, they have also pointed out the difficulty of treating produced water for reinjection or disposal. As polymers tend to concentrate in such streams, oil/water separation becomes more difficult and larger separators are required to increase residence time [17]. Furthermore, if the produced water is meant to be discharged into the environment, then the oil content of the effluent should be within the established offshore environmental regulations.

Flotation is the last treatment stage in offshore oil production units and is responsible for suiting water discharge regulatory specifications [18]. Hence, maintaining flotation units at a high level of efficiency is essential to protect the environment and make oil production sustainable.

It has been reported though that EOR chemicals may decrease flotation efficiency. According to Zheng et al. [19], the presence of surfactants and polymers can profoundly affect the performance of flotation units. Argillier et al. [12] have stated that these products may adversely influence bubble size distribution. Polymers may cause oil-water emulsion stabilization and affect the performance of the flotation unit [13]. The presence of surfactants in EOR produced water can also contribute for oil-water emulsion stabilization. However, on the other hand, surfactants can inhibit bubble coalescence [20], affecting positively the gas holdup of the flotation units.

Flotation is a gravitational separation method that employs gas bubbles in such a way that they attach to oil droplets, enhancing their buoyancy and allowing them to be skimmed from the surface of produced water [21]. To accomplish this goal efficiently, Moosai and Dawe [22] point out the vital importance of bubble size in gas flotation. Robinson [23] clarifies that, according to Stokes' Law, the smaller the bubble diameter in produced water, the smaller the bubble rises and therefore the more frequently bubbles collide with the oil droplets, increasing flotation efficiency.

Saththasivam et al. [24] confirmed the importance of reducing gas bubble size to increase flotation efficiency, finding that size reduction makes collision more likely. In their water/air/n-dodecane system, Oliveira et al. [25] increased the water salinity in order to decrease the size of air bubbles. Their results showed that the probability of collision between bubbles and $n$-dodecane increased, thus the flotation efficiency improved. Rajak et al. [26] have indeed confirmed the abovementioned relations between bubble size and water salinity. They have enhanced flotation efficiency to separate oil from oil-in-water emulsions by increasing water salinity.

The above-mentioned makes it clear how important is to measure the effects of EOR chemicals (polymer and surfactant) and produced water composition (salinity) on bubble size distribution in order to understand and improve gas flotation when processing EOR effluents.

Bubble columns, often used to perform chemical reactions and for wastewater treatment [27], have also been used to assess the hydrodynamics of multiphase flows because of their simple geometry and lack of moving parts [28-31]. These advantages allow researchers to easily measure the size of gas bubbles using image acquisition and data analysis [32-34]. Another important factor that can be measured is the gas holdup [35-38]. Unlike bubble size measurement, which is a local measurement, gas holdup is a global measurement and can be used to calculate residence time. It can also be used to assess interfacial area, mass and heat transfer between the phases involved in the multiphase flow $[39,40]$.

Li et al. [38] studied the effect of process variables on gas holdup of a cyclone-static micro-bubble flotation column for treatment of oily water. According to their results, varying holdup from $9.7 \%$ to $10.5 \%$, improved oil removal from $95.2 \%$ to $99 \%$. Therefore, a marginal improvement in holdup can generate considerable increases in equipment performance, while the opposite is also true: a reduction in holdup can significantly affect the efficiency of flotation units.

The purpose of this work is thus to evaluate the influence of polymers, surfactants and produced water salinity on gas bubble size and holdup. A laboratory bubble column has been used and the influence of superficial gas velocity has also been assessed. Factorial design technique has been applied to identify the main factors and interactions that effectively impact bubble size and gas holdup. Results help to characterize physical properties of EOR effluents and establish how bubble size and gas holdup are affected by EOR chemicals and superficial gas velocities.

\section{Materials and methods}

\subsection{Synthetic produced water}

Synthetic produced water has been prepared by adding sodium chloride, polymer and surfactant at different concentrations. As the focus of the present work is the gas-water interface, no oil has been added to the synthetic produced water.

Based on the works of Liu [41], Zhao [42], Zhao et al. [43], Flaaten [44], Barnes et al. [45], and Solairaj et al. [46] the adopted range for salinity in the experimental set was from 60 to $200 \mathrm{~g} / \mathrm{L}$ of sodium chloride $(\mathrm{NaCl})$.

The polymer used is a copolymer of acrylamide and 2-Acrylamido-2-Methylpropane Sulfonate (AMPS). Its molar mass is about $12 \times 10^{6} \mathrm{~g} / \mathrm{mol}$ [47]. It has been supplied by $S N F$ and is used in real EOR applications. According to Liu et al. [48] and [49], polymer concentration in EOR produced water varies from 100 to $2000 \mathrm{mg} / \mathrm{L}$ and this is the range investigated in the present work.

The surfactant used in the synthetic produced water was Sodium Dodecylbenzenesulfonate (SDBS), supplied by LABSYNTH. According to Olajire [1] and Miao et al. [5] such surfactant has been used in advanced EOR systems and is therefore of interest for industrial application. In accordance to the work of Liu et al. [49], the surfactant concentration lies in the range of $0-100 \mathrm{mg} / \mathrm{L}$ and so it has been varied in the present work.

Brine has been prepared by dissolving sodium chloride in tap water at the desired concentration. At the same time, 
a polymer stock solution has been prepared by gently shaking the product in tap water till it dissolved. For polymer-injection-like effluents, volumes of the brine and polymer stock solution were mixed. For surfactantpolymer-injection-like effluents, surfactant was added to the mixture of brine and polymer stock solution, according to the desired concentration.

\subsubsection{Physical properties of synthetic produced water}

Density, viscosity and surface tension measurements have been performed to characterize the different compositions of synthetic produced water for the tests in the bubble column. All analyses have been performed at $20^{\circ} \mathrm{C}$, since tests in the column have also been conducted at this temperature.

Density analyses have been performed in an Anton Paar DMA 4500 digital density meter based on ASTM D4052-09.

Viscosity analyses have been carried out in an Anton Paar Physica MCR 501 rheometer based on DIN 13343, DIN 1342, DIN 3219, DIN 51810, DIN 53019, DIN 54458, ISO 3219, ISO 6721-1 and USP 912 international standards.

Surface tension analyses have been performed on a Teclis Tracker S. tensiometer using the procedures described in ISO 304/1985, ISO 6889/1986, and ASTM D1331-14 international standards.

\subsection{Bubble column}

The bubble column used for the experiments is $2 \mathrm{~m}$ high and has $5.4 \mathrm{~cm}$ of internal diameter. At the bottom of the column, air is injected through a metal distributor with 57 holes of $0.5 \mathrm{~mm}$ in diameter, evenly spaced by $6 \mathrm{~mm}$.

The column was operated at $20^{\circ} \mathrm{C}$ in semi-batch mode. It has been filled with synthetic produced water and air bubbles have been injected at different superficial gas velocities.

Preliminary experiments in the lab column have shown that the presence of polymers accelerated the transition to the heterogeneous flow regime, as also noted by Ruzicka et al. [50], which makes it more difficult to evaluate bubble sizes. Therefore, following Bordel et al. [51], the present work has then been limited to the bubbly flow regime, where the formation of clusters and swarms is low. Besides, surfactants are expected to form foam which also disturbs the bubble column operation and its data acquisition. Air superficial velocities have been set between 0.25 and $0.5 \mathrm{~cm} / \mathrm{s}$ in order to avoid clusters, swarms and foam.

Figure 1 shows the schematic of the bubble column in which the tests were performed. Air flow has been controlled using needle valves and has been measured using a Coriolis meter - FQIT (Micromotion, model CMF10M, with flow transmitter Model 2700). Air-supply pressure has been measured with an absolute pressure gauge in the bottom of the column (Yokogawa, model EJA510E). Image acquisition for bubble size assessment has been carried out at the point A (Fig. 1). In order to calculate gas holdup, two Pressure Indicators (PIT) have been installed. The first one has been placed $260 \mathrm{~mm}$ from the air distributor and the second, from 1740 mm, as can be seen in Figure 1.

\subsection{Assessing bubble size}

The Sauter mean diameter is commonly used in bubble column and flotation studies. According to Pérez-Garibay et al. [52], its use is justified by the fact that the flotation rate is easily related to the surface area of the bubbles.

The mean Sauter diameter of the bubbles has been obtained by image acquisition and analysis at the point A (Fig. 1). An IDT NanoSense MKIII high speed camera with Nikon Nikkor $60 \mathrm{~mm}$ F2.8 lens have been used. At each section photos were taken using three different exposure times $(150,170$ and $200 \mu \mathrm{s})$. For each exposure time, 200 images were obtained and have been processed using the Shadow sizing module tool of the Dantec DynamicStudio ${ }^{\circledR}$ software.

\subsection{Assessing gas holdup}

According to Li et al. [38], equation (1) can be used to calculate the gas holdup $\varepsilon$ :

$$
\varepsilon=1-\left(\frac{\Delta P}{\rho_{l} \times g \times h}\right),
$$

where $\Delta P$ is the differential pressure measured between the PITs in the column, $\rho_{l}$ is the specific mass of the liquid phase, $g$ is gravity acceleration and $h$ is the distance between pressure measurements.

\subsection{Design of experiment}

In order to assess the influence of salinity, polymer concentration, surfactant concentration and superficial gas velocity in bubble size and gas holdup, the $2^{k}$ complete factorial design has been used. Therefore, each of the aforementioned variables have been evaluated at two values, these being the extreme values of interest. These values have been defined above and are now summarized in Table 1. In coded variables, the lowest value is associated to -1 and the highest to +1 , as also shown in Table 1 . A generic variable $\varphi$ is related to its coded counterpart $\phi$ through:

$$
\emptyset=\frac{\varphi-\left(\varphi_{\text {high }}+\varphi_{\text {low }}\right) / 2}{\left(\varphi_{\text {high }}-\varphi_{\text {low }}\right) / 2}
$$

Bubble diameter and gas holdup assays have been carried out in duplicates and the average of these experimental values have been taken. Additionally, for holdup assessment, two more experiments have been performed at the central point of experimental design, that is, with $130 \mathrm{~g} / \mathrm{L}$ of $\mathrm{NaCl}, 1050 \mathrm{mg} / \mathrm{L}$ of polymer, $50 \mathrm{mg} / \mathrm{L}$ of surfactant and superficial gas velocity of $0.375 \mathrm{~cm} / \mathrm{s}$.

Analysis of Variance (ANOVA) has been used to identify the independent variables and their interactions that were statistically significant in affecting bubble size and gas holdup. The statistical evaluation has been carried out with the MINITAB ${ }^{\mathbb{B}}$ statistical software. 


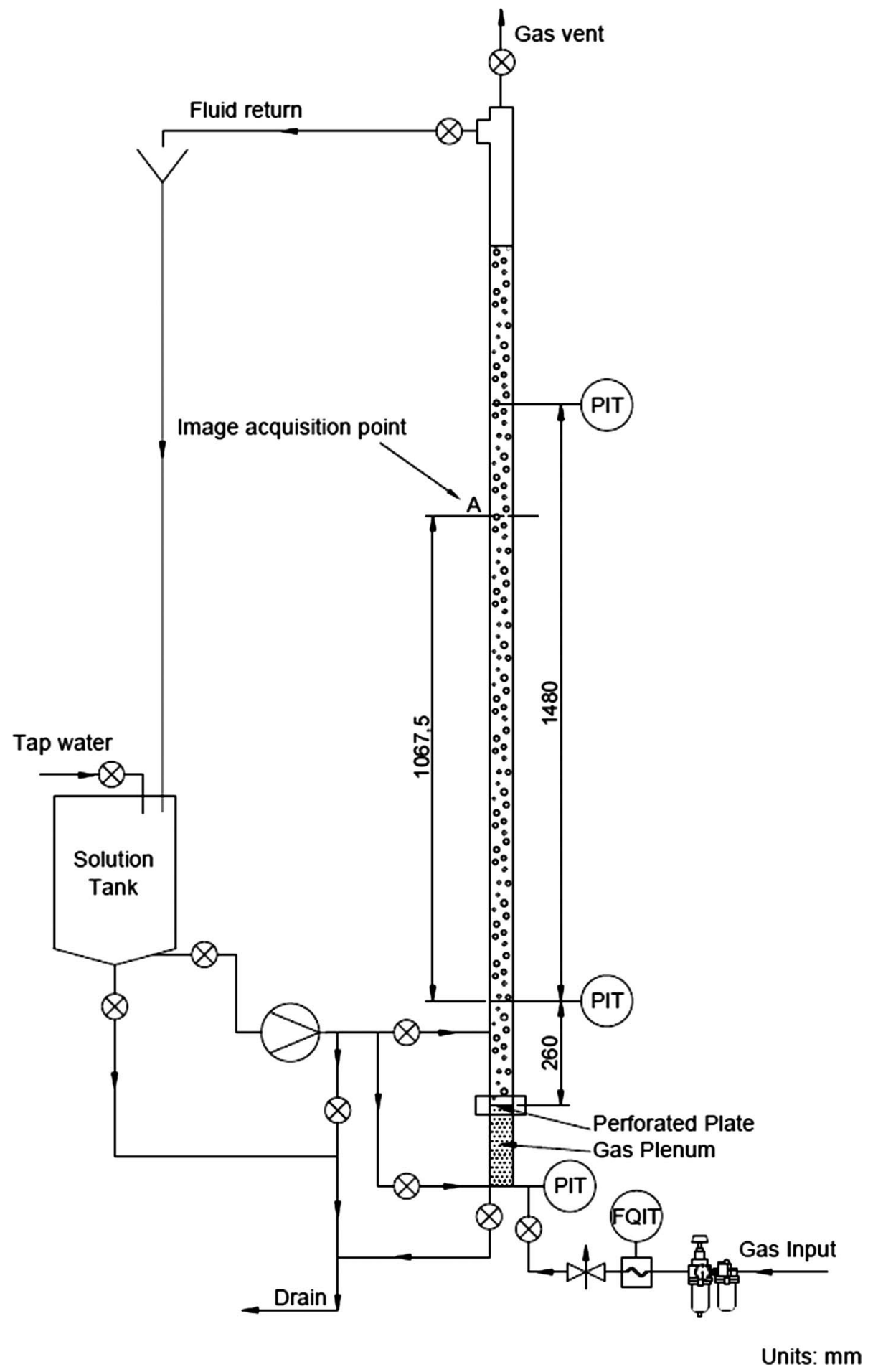

Fig. 1. Experimental setup to assess bubble size and gas holdup.

\section{Results and discussion}

Table 2 shows how EOR chemicals affect physical properties of the synthetic produced water.

Apparent viscosity $\mu_{\text {app }}$ has been evaluated for a general power law fluid and can be expressed as in equation (3):

$$
\mu_{\text {app }}=K \gamma^{n-1},
$$

where $K$ stands for the consistency index in dynamic viscosity units, $\gamma$ is the shear rate and $n$ is a non-dimensional parameter known as the flow behavior index, since its value indicates whether the flow is Newtonian $(n=1)$, 
Table 1. $2^{4}$ complete factorial design for bubble diameter and gas holdup.

\begin{tabular}{lcc}
\hline Factors & Low level $(-1)$ & High level $(+1)$ \\
\hline Salinity $(\mathrm{NaCl})(\mathrm{g} / \mathrm{L})$ & 60 & 200 \\
Polymer concentration $(\mathrm{mg} / \mathrm{L})$ & 100 & 2000 \\
Surfactant concentration $(\mathrm{mg} / \mathrm{L})$ & 0 & 100 \\
Superficial gas velocity $(\mathrm{cm} / \mathrm{s})$ & 0.25 & 0.50 \\
\hline
\end{tabular}

Table 2. Physical properties of synthetic produced water.

\begin{tabular}{lcccccc}
\hline $\begin{array}{c}\mathrm{NaCl} \\
(\mathrm{g} / \mathrm{L})\end{array}$ & $\begin{array}{c}\text { Polymer } \\
(\mathrm{mg} / \mathrm{L})\end{array}$ & $\begin{array}{c}\text { Surfactant } \\
(\mathrm{mg} / \mathrm{L})\end{array}$ & $\begin{array}{c}\text { Specific mass } \\
\left(\mathrm{kg} / \mathrm{m}^{3}\right)\end{array}$ & $\begin{array}{c}\text { Surface tension } \\
(\text { dina } / \mathrm{cm})\end{array}$ & $\begin{array}{c}\text { Consistency index, } \\
K\left(\mathrm{mPa} \mathrm{s}^{n}\right)\end{array}$ & $\begin{array}{c}\text { Flow behavior } \\
\text { index, } n\end{array}$ \\
\hline 60 & 100 & 0 & 1041.6 & 70.8 & 2.04 & 0.915 \\
60 & 2000 & 0 & 1042.3 & 72.8 & 22.87 & 0.779 \\
200 & 100 & 0 & 1126.7 & 72.8 & 1.79 & 0.978 \\
200 & 2000 & 0 & 1125.3 & 74.2 & 24.05 & 0.791 \\
60 & 100 & 100 & 1039.7 & 33.5 & 0.98 & 1.032 \\
60 & 2000 & 100 & 1040.8 & 30.7 & 24.64 & 0.761 \\
200 & 100 & 100 & 1124.8 & 42.5 & 4.19 & 0.831 \\
200 & 2000 & 100 & 1123.2 & 42.3 & 21.66 & 0.790 \\
130 & 1050 & 50 & 1083.4 & 35.7 & 9.33 & 0.827 \\
\hline
\end{tabular}

non-Newtonian pseudoplastic $(n<1)$ or non-Newtonian dilatant $(n>1)$.

It can be seen in Table 2 that high concentration of polymer increases viscosity significantly and is the main factor responsible for a non-Newtonian pseudoplastic fluid behavior. Density is mainly affected by high concentrations of $\mathrm{NaCl}$ and surface tension is drastically reduced with high concentrations of surfactant. Such evidences support how challenging can be the separation processes in flotation cells.

Table 3 shows how EOR chemicals and superficial gas velocity affect bubble size (Sauter mean diameter) and gas holdup. It can be seen that as superficial gas velocity increases, both bubble size and gas holdup increase; an increase in polymer concentration increases bubble size, but gas holdup decreases when surfactant is not present; the presence of surfactant decreases bubble size, and increases gas holdup even at high polymer concentrations; salinity seems to not have a significant effect on bubble size and gas hold up.

In order to quantify how bubble size and gas holdup are affected by superficial gas velocity and EOR chemicals, regression analysis and ANOVA combined with F-test have been carried out. This also allows evaluation of nonsignificant terms $(p>0.05)$.

A first-order model with interactions has been fitted for bubble size and a model reduction was performed to neglect the non-significant factors and interactions. All interactions and salinity have been considered non-significant, being excluded from the model. The corresponding ANOVA data is presented in Table 4, confirming previous analysis of Table 3: polymer concentration, surfactant concentration, and superficial gas velocity have strong effect on bubble diameter, as confirmed by their respective null $p$-values and by Figure 2, where the main effects of the variables on bubble size are highlighted.

It can be seen in Figure 2 that increasing only polymer concentration from 100 to $2000 \mathrm{mg} / \mathrm{L}$ can lead to a growth of more than $40 \%$ in bubble diameter; that $100 \mathrm{mg} / \mathrm{L}$ of surfactant only can decrease bubble size by $20 \%$; that only doubling superficial gas velocity increases bubble diameter by less than $10 \%$; and that salinity only does not play a significant role in the range studied.

The model obtained for bubble Sauter mean diameter (in $\mathrm{mm}$ ) is presented in equation (4):

$$
d=5.82+0.98 P-0.53 S+0.24 V,
$$

where $d$ stands for bubble Sauter mean diameter and $P, S$, and $V$ correspond to the values of polymer concentration, surfactant concentration and superficial gas velocity, respectively, in coded variables (from -1 to +1 ). Since a reasonable fit between predicted and experimental bubble diameter has been obtained $\left(R^{2}=0.9537 /\right.$ adjusted $R^{2}=0.9422$ ), one can assume that the developed model predicts experimental data satisfactorily.

A first-order model with interactions has also been fit to relate salinity, polymer concentration, surfactant concentration and superficial gas velocity with gas holdup. Then, a model reduction has been performed to neglect the non-significant terms. The corresponding ANOVA data is presented in Table 5.

It can be seen in Table 5 that the parameters that significantly affect gas holdup are superficial gas velocity 
Table 3. Results of factorial design for bubble diameter and gas holdup.

\begin{tabular}{lccccc}
\hline $\begin{array}{l}\mathrm{NaCl} \\
(\mathrm{g} / \mathrm{L})\end{array}$ & $\begin{array}{c}\text { Polymer } \\
(\mathrm{mg} / \mathrm{L})\end{array}$ & $\begin{array}{c}\text { Surfactant } \\
(\mathrm{mg} / \mathrm{L})\end{array}$ & $\begin{array}{c}\text { Superficial gas } \\
\text { velocity }(\mathrm{cm} / \mathrm{s})\end{array}$ & $\begin{array}{c}\text { Bubble } \\
\text { diameter }(\mathrm{mm})\end{array}$ & Holdup $(\%)$ \\
\hline 60 & 100 & 0 & 0.250 & 4.8 & 1.3 \\
60 & 100 & 0 & 0.500 & 5.2 & 2.4 \\
60 & 2000 & 0 & 0.250 & 7.3 & 1.1 \\
60 & 2000 & 0 & 0.500 & 5.9 & 1.6 \\
200 & 100 & 0 & 0.250 & 5.7 & 1.0 \\
200 & 100 & 0 & 0.500 & 6.8 & 2.1 \\
200 & 2000 & 0 & 0.250 & 7.8 & 1.1 \\
200 & 2000 & 0 & 0.500 & 4.3 & 1.9 \\
60 & 100 & 100 & 0.250 & 4.4 & 2.5 \\
60 & 100 & 100 & 0.500 & 5.7 & 1.8 \\
60 & 2000 & 100 & 0.250 & 6.4 & 2.9 \\
60 & 2000 & 100 & 0.500 & 4.5 & 1.2 \\
200 & 100 & 100 & 0.250 & 4.5 & 2.5 \\
200 & 100 & 100 & 0.500 & 5.9 & 1.5 \\
200 & 2000 & 100 & 0.250 & 6.6 & 2.7 \\
200 & 2000 & 100 & 0.500 & & 2.2 \\
130 & 1050 & 50 & 0.375 & & \\
\hline
\end{tabular}

Table 4. ANOVA of the first-order model obtained for bubble size data.

\begin{tabular}{lccccc}
\hline Source & $d f$ & Sum of squares & Mean square & $F$-value & $p$-value \\
\hline Model & 3 & 20.8719 & 6.9573 & 82.46 & 0.000 \\
Linear & 3 & 20.8719 & 6.9573 & 82.46 & 0.000 \\
Polymer & 1 & 15.4056 & 15.4056 & 182.59 & 0.000 \\
Velocity & 1 & 0.9506 & 0.9506 & 11.27 & 0.006 \\
Surfactant & 1 & 4.5156 & 4.5156 & 53.52 & 0.000 \\
Error & 12 & 1.0125 & 0.0844 & & \\
Total & 15 & 21.8844 & & & \\
\hline
\end{tabular}

ANOVA, Analysis of Variance.

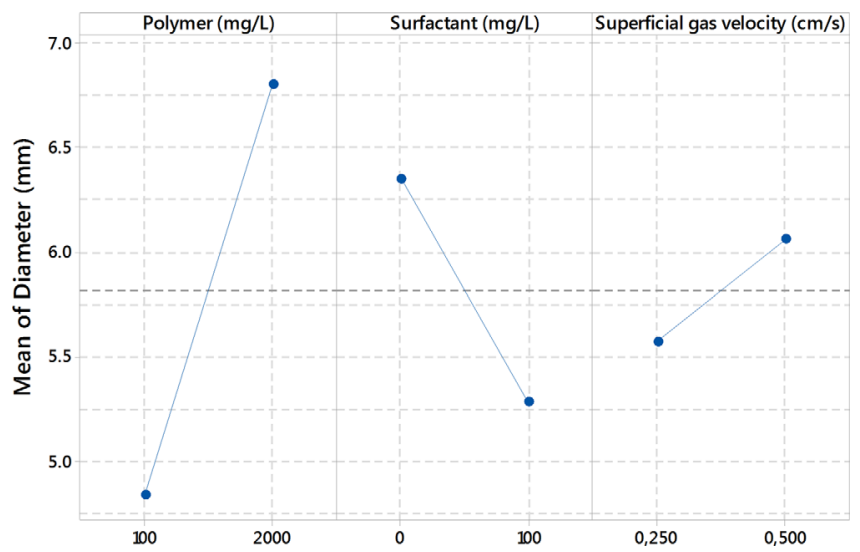

Fig. 2. Individual main effects for bubble diameter. and surfactant concentration $(p<0.05)$. Polymer concentration does not affect directly holdup, as a main factor, however its influence on this parameter occurs through its interaction with surfactant.

Figure 3 confirms the importance of superficial gas velocity and surfactant concentration on holdup. It can be seen that only the addition of only $100 \mathrm{mg} / \mathrm{L}$ of surfactant causes an increase in holdup that exceeds $25 \%$. It can also be noted that only doubling superficial gas velocity produces an increase of roughly $70 \%$ in holdup.

Figure 4 shows the influence of variable interactions on holdup. It can be seen that polymer-surfactant interaction affects holdup differently, depending on surfactant concentration: when the surfactant concentration is low, an increase in polymer concentration decreases holdup; at a concentration of $50 \mathrm{mg} / \mathrm{L}$ of surfactant, holdup is not 
Table 5. ANOVA of the first-order model obtained for gas holdup data.

\begin{tabular}{lccccc}
\hline Source & $d f$ & Sum of squares & Mean square & $F$-value & $p$-value \\
\hline Model & 3 & 5.7350 & 1.91167 & 41.73 & 0.000 \\
Linear & 2 & 5.3125 & 2.65625 & 57.98 & 0.000 \\
Surfactant & 1 & 0.9025 & 0.90250 & 19.70 & 0.001 \\
Velocity & 1 & 4.4100 & 4.41000 & 96.26 & 0.000 \\
Two-way interaction & 1 & 0.4225 & 0.42250 & 9.22 & 0.010 \\
Polymer $\times$ Surfactant & 1 & 0.4225 & 0.42250 & 9.22 & 0.010 \\
Error & 13 & 0.5956 & 0.04581 & & \\
Total & 16 & 6.3306 & & & \\
\hline
\end{tabular}

ANOVA, Analysis of Variance.

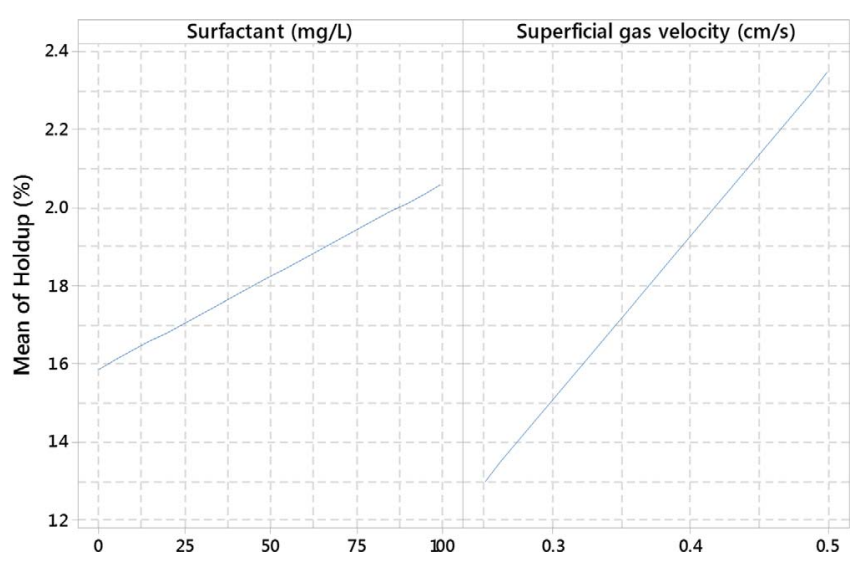

Fig. 3. Individual main effects for gas holdup.

affected by polymer concentration; while the presence of $100 \mathrm{mg} / \mathrm{L}$ of surfactant, increases holdup when polymer concentration is increased. This behavior may be associated with the fact that bubble diameter decreases in the presence of high concentration of surfactant.

The first-order model obtained for gas holdup is presented in equation (5) for coded variables. The coefficient of determination $\left(R^{2}\right)$ is 0.9059 , which ensures the model can explain $90 \%$ of the variability. The adjusted $R^{2}(0.8842)$ is in reasonable agreement with the $R^{2}$ value and therefore the gas holdup model can also be considered satisfactory:

$$
\varepsilon(\%)=1.82+0.24 S+0.52 \mathrm{~V}+0.16 P \times S .
$$

It is worth to relate the effect of EOR chemicals on bubble size and gas holdup with changes in the physical properties of synthetic produced water. As polymer increases fluid viscosity, as discussed in Table 2, it can be inferred that viscosity is responsible for increasing bubble size and affects gas holdup differently, depending on surfactant concentration. As surfactant reduces surface tension, this physical property is responsible for decreasing bubble size and increasing gas holdup. Thus, the presence of surfactant inhibits the effect of polymer in increasing bubble size and makes

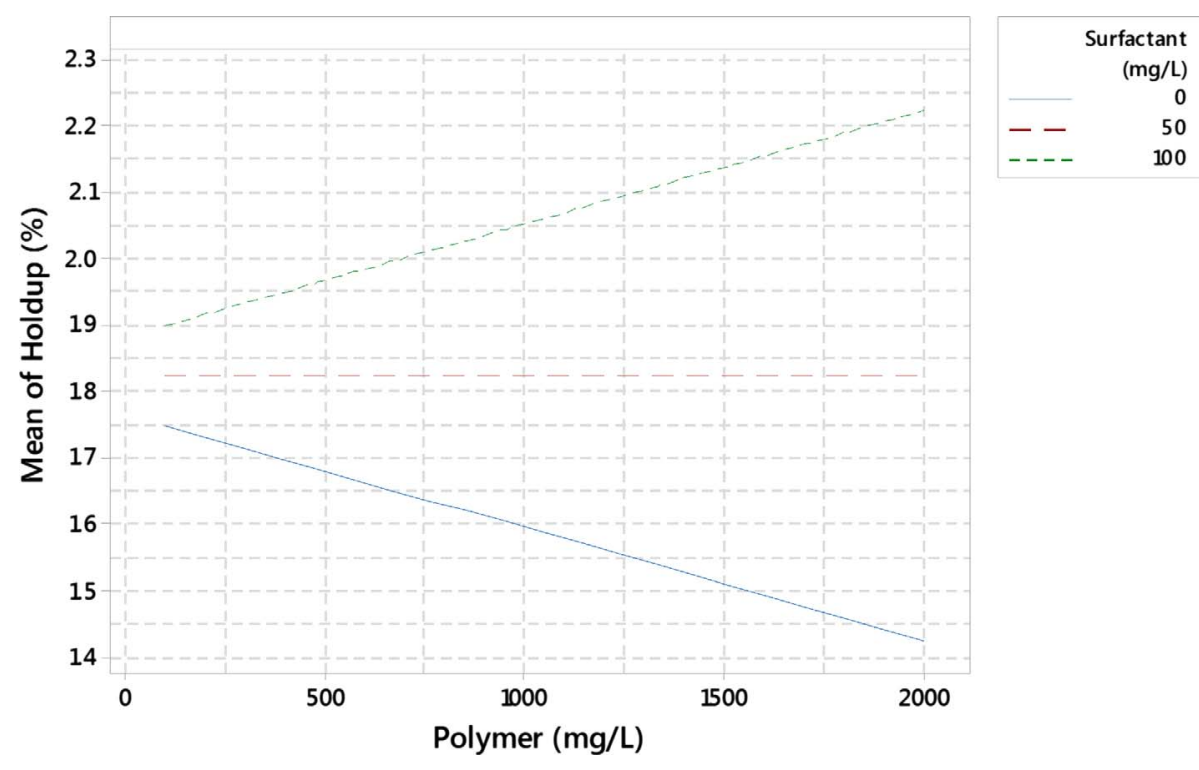

Fig. 4. Effects of the interaction in the first-order model for gas holdup. 
it increase gas holdup. For the range studied, salinity seems to weakly influence bubble size and gas holdup.

\section{Conclusion}

The present work has used a bubble column to assess the impact of EOR chemicals and superficial gas velocity on bubble size and gas holdup. Factorial experiments have been designed to identify the main factors and their interactions that significantly affect these operational parameters of bubble columns.

The resulting synthetic produced water samples have been characterized and their main physical properties have been determined. It has been shown that they behave as non-Newtonian fluids.

Experimental results did show that both the increase in superficial gas velocity and the presence of surfactant favor a significant increase in gas holdup. On the other hand, an increase in polymer concentration only increases gas holdup when surfactant is present at high concentrations.

Polymer concentration favors an increase in bubble size, while the presence of surfactant decreases bubble diameter. Salinity seems to weakly influence bubble size and gas holdup.

The effects of EOR chemicals are eventually related to changes in physical properties of the continuous phase, the synthetic produced water. The presence of polymer increases viscosity and intensifies non-Newtonian behavior and surfactants drastically decrease surface tension.

Experiments have provided clear insights of how EOR chemicals influence bubble size and gas holdup in a laboratory bubble column. As a whole, it can be said that polymers are expected to be detrimental to produced water treatment, since they tend to decrease gas holdup and increase bubble size in the absence of surfactants, rendering flotation-like systems less efficient. These results are therefore of crucial importance for proper treatment of EOR effluents, since changes in the composition of produced water can severely impact the efficiency of unit operations that rely on gas bubble size for the separation process. Further experiments in the presence of oil droplets would allow to confirm the present conclusions and this remains for future work.

Acknowledgments. The authors would like to thank PETROBRAS and UNIFEI for their support for this study.

\section{References}

1 Olajire A.A. (2014) Review of ASP EOR (alkaline surfactant polymer enhanced oil recovery) technology in the petroleum industry: Prospects and challenges, Energy 77, 963-982.

2 Thomas S. (2008) Enhanced oil recovery - an overview, Oil Gas Sci. Technol. - Rev. IFP Energies nouvelles 63, 9-19.

3 Douarche F., Da Veiga S., Feraille M., Enchéry G., Touzani S., Barsalou R. (2014) Sensitivity analysis and optimization of surfactant-polymer flooding under uncertainties, Oil Gas Sci. Technol. - Rev. IFP Energies nouvelles 69, 603-617.
4 Raffa P., Broekhuis A.A., Picchioni F. (2016) Polymeric surfactants for enhanced oil recovery: A review, J. Pet. Sci. Eng. 145, 723-733.

5 Miao L., Li F., Sun D., Wu T., Li Y. (2015) Interfacial and electrokinetic properties of asphaltenes and alkali/ surfactant/polymer in produced water system, J. Pet. Sci. Eng. 133, 18-28.

6 Rambeau O., Jacob M., Rondon M., Jouenne S., Cordelier P. (2014) A tool to tackle the challenges of the treatment of the back produced viscosified water, in: International Petroleum Technology Conference, 19-22 January, Doha, Qatar.

7 Santos R.G., Loh W., Bannwart A.C., Trevisan O.V. (2014) An overview of heavy oil properties and its recovery and transportation methods, Braz. J. Chem. Eng. 31, 571-590.

8 Yu L., Sang Q., Dong M. (2018) Enhanced oil recovery ability of branched preformed particle gel in heterogeneous reservoirs, Oil Gas Sci. Technol. - Rev. IFP Energies nouvelles 73, 65.

9 Adasani A.A., Bai B. (2011) Analysis of EOR projects and updated screening criteria, J. Pet. Sci. Eng. 79, 10-24.

10 Ma B., Gao B., Yue Q. (2013) Study on emulsification stability of wastewater produced by polymer flooding, J. Pet. Sci. Eng. 110, 27-31.

11 Raney K.H., Ayirala S., Chin R.W., Verbeek P. (2012) Surface and subsurface requirements for successful implementation of offshore chemical enhanced oil recovery, in: SPE Production 85 Operations 27, 3, 294-305. SPE-155116PA. doi: 10.2118/155116-PA.

12 Argillier J.-F., Henaut I., Nolk C., Vieira R., Roca Leon F., Aanesen B. (2014) Influence of chemical EOR on topside produced water management, in: SPE Improved Oil Recovery Symposium, 12-16 April, Tulsa, OK, USA. SPE-169067-MS.

13 Argillier J.-F., Dalmazzone C., Henaut I., Mouazen M., Noik C., Boufarguine M. (2013) Methodological approach for analyzing the impact of chemical EOR on surface processes, in: SPE International Symposium on Oilfield Chemistry, 8-10 April, The Woodlands, TX, USA. SPE 164098. doi: 10.2118/164098-MS.

14 Zheng J., Chen B., Thanyamanta W., Hawboldt K., Zhang B., Liu B. (2016) Offshore produced water management: A review of current practice and challenges in harsh/ Arctic environments, Mar. Pollut. Bull. 104, 7-19.

15 Wang Z., Zhao L., Li F., He J., Chen L. (1999) Characteristics study of hydrocyclone used for separating polymerflood produced-water, in: Proceedings of the 1999 9th International Offshore and Polar Engineering Conference (ISOPE-99), May 30-June 4, Brest, France.

16 Chen H., Tang H., Gong X., Wang J., Liu Y., Duan M., Zhao F. (2015) Effect of partially hydrolyzed polyacrylamide on emulsification stability of wastewater produced from polymer flooding, J. Pet. Sci. Eng. 133, 431-439.

17 Thomas A., Gaillard N., Favero C. (2012) Some key features to consider when studying acrylamide-based polymers for chemical enhanced oil recovery, Oil Gas Sci. Technol. - Rev. IFP Energies nouvelles 67, 887-902.

18 Walsh J.M. (2015) Produced-water-treatment systems: Comparison of North Sea and deepwater Gulf of Mexico, in: SPE Annual Technical Conference and Exhibition, 8-10 October, San Antonio, TX, USA. SPE 159713.

19 Zheng F., Quiroga P., Sams G. (2011) Challenges in processing produced emulsion from chemical enhanced oil recovery - polymer flood using polyacrylamide, in: SPE Enhanced Oil Recovery Conference, 19-21 July, Kuala Lumpur, Malaysia. SPE 144322. 
20 Azizi F., Al Taweel A.M. (2007) Population balance simulation of gas-liquid contacting, Chem. Eng. Sci. 62, 7436-7445.

21 Al-Shamrani A.A., James A., Xiao H. (2002) Separation of oil from water by dissolved air flotation, Colloids Surf. A Physicochem. Eng. Aspects 209, 15-26.

22 Moosai R., Dawe R.A. (2003) Gas attachment of oil droplets for gas flotation for oily wastewater cleanup, Sep. Purif. Technol. 33, 303-314.

23 Robinson D.L. (2013) Treatment and discharge of produced waters offshore, Filtr. Sep. 50, 2, 20-23.

24 Saththasivam J., Loganathan K., Sarp S. (2016) An overview of oil-water separation using gas flotation systems, Chemosphere 144, 671-680.

25 Oliveira R.C.G., Gonzalez G., Oliveira J.F. (1999) Interfacial studies on dissolved gas flotation of oil droplets for water purification, Colloids Surf. A Physicochem. Eng. Aspects 154, 127-135.

26 Rajak V.K., Relish K.K., Kumar S., Mandal A. (2015) Mechanism and kinetics of separation of oil from oil in water emulsion by air flotation, Pet. Sci. Technol. 33, 1861-1868.

27 Forret A., Schweitzer J.M., Gauthier T., Krishna R., Schweich D. (2006) Scale up of slurry bubble reactors, Oil Gas Sci. Technol. - Rev. IFP Energies nouvelles 61, 443-458.

28 Haque M.W., Nigam K.D.P., Srivastava V.K., Joshi J.B., Viswanathan K. (1987) Studies on mixing time in bubble columns with pseudoplastic (carboxymethyl) cellulose solutions, Ind. Eng. Chem. Res. 26, 82-86.

29 Hol P.D., Heindel T.J. (2005) Local gas holdup variation in a fiber slurry, Ind. Eng. Chem. Res. 44, 4778-4784.

30 Mudde R.F., Harteveld W.K., van den Akker H.E.A. (2009) Uniform flow in bubble columns, Ind. Eng. Chem. Res. 48, 148-158.

31 Youssef A.A., Hamed M.E., Grimes J.T., Al-Dahhan M.H., Duduković M.P. (2013) Hydrodynamics of pilot-scale bubble columns: Effect of internals, Ind. Eng. Chem. Res. 52, 43-55.

32 Hagesaether L., Jakobsen H.A., Svendsen H.F. (2002) Modeling of the dispersed-phase size distribution in bubble columns, Ind. Eng. Chem. Res. 41, 2560-2570.

33 Botello-Álvarez J.E., Baz-Rodríguez S.A., González-Garcia R., Estrada-Baltazar A., Padilla-Medina J.A., GonzálezAlatorre G., Navarrete-Bolaños J.L. (2011) Effect of eletrolytes in aqueous solution on bubble size in gas-liquid bubble columns, Ind. Eng. Chem. Res. 50, 12203-12207.

34 Jin H., Lim D.H., Lim H., Kang Y., Jung H., Kim S.D. (2012) Demarcation of large and small bubbles in viscous slurry bubble columns, Ind. Eng. Chem. Res. 51, 2062-2069.

35 Lee Y.H., Kim Y.J., Kelkar B.G., Weinberger C.B. (1985) A simple digital sensor for dynamic gas holdup measurements in bubble columns, Ind. Eng. Chem. Res. 24, 105-107.

36 Su X., Heindel T.J. (2005) Modeling gas holdup in gas-liquidfiber semibatch bubble columns, Ind. Eng. Chem. Res. 44, 9355-9363.

37 Hooshyar N., Hamersma P.J., Mudde R.F., Ommen J.R. (2010) Gas fraction and bubble dynamics in structured slurry bubble columns, Ind. Eng. Chem. Res. 49, 10689-10697.

38 Li X., Zhu W., Liu J., Zhang J., Xu H., Deng X. (2016) Gas holdup in cyclone-static micro-bubble flotation column, Environ. Technol. 37, 7, 785-794.
39 Lau R., Peng W., Velazquez-Vargas L.G., Yang G.Q., Fan L.-S. (2004) Gas-liquid mass transfer in high-pressure bubble columns, Ind. Eng. Chem. Res. 43, 1302-1311.

40 Saleh S.N., Mohammed A.A., Al-Jubory F.K., Shahzad B. (2018) CFD assessment of uniform bubbly flow in a bubble column, J. Pet. Sci. Eng. 161, 96-107.

41 Liu S. (2007) Development of high-performance surfactants for difficult oils. $222 \mathrm{f}$. Thesis (Doctor of Philosophy), Rice University, Houston, TX.

42 Zhao P. (2007) Development of high-performance surfactants for difficult oils. $122 \mathrm{f}$. Dissertation (Master of Science in Engineering), Faculty of the Graduate School, University of Texas, Austin.

43 Zhao P., Jackson A.C., Britton C., Kim D.H., Britton L.N., Levitt D.B., Pope G.A. (2008) Development of highperformance surfactants for difficult oils, in: $S P E / D O E$ Improved Oil Recovery Symposium, 20-23 April, Tulsa, OK, USA. SPE 113432.

44 Flaaten A.K. (2007) Experimental study of microemulsion characterization and optimization in enhanced oil recovery: A design approach for reservoirs with high salinity and hardness. $284 \mathrm{f}$. Thesis (Master of Science in Engineering), Faculty of the Graduate School, University of Texas, Austin.

45 Barnes J.R., Smit J.P., Smit J.R., Shpakoff P.G., Raney K.H., Puerto M.C. (2008) Development of surfactants for chemical flooding at difficult reservoir conditions, in: $S P E$ / DOE Improved Oil Recovery Symposium, 20-23 April, Tulsa, OK, USA. SPE 113313.

46 Solairaj S., Britton C., Kim D.H., Weerasooriya U., Pope G.A. (2012) Measurement and analysis of surfactant retention, in: SPE Improved Oil Recovery Symposium, 14-18 April, Tulsa, OK, USA, SPE-154247-MS.

47 Rashidi M. (2010) Physico-chemistry characterization of sulfonated polyacrylamide polymers for use in polymer flooding, Thesis (Doctor of Philosophy), The University of Bergen, Bergen, Norway.

48 Liu Y., Wang Z., Li X., Le X., Wang X.A.S.P. (2014) Flooding produced water: Management, evaluation, disposal and reuse, in: SPE Middle East Health, Safety, Environment \&5 Sustainable Development Conference ${ }^{3}$ Exhibition, 22-24 September, Doha, Qatar. SPE-170396-MS.

49 Liu Y., Wang Z., Zhuge X., Zhang H., Le X. (2013) An environmentally-friendly method for disposal of the ASP flooding produced water, in: SPE Artic and Extreme Environments Conference \& Exhibition, 15-17 October, Moscow, Russia. SPE 166965.

50 Ruzicka M.C., Drahos J., Mena P.C., Teixeira J.A. (2003) Effect of viscosity on homogeneous-heterogeneous flow regime transition in bubble columns, Chem. Eng. J. 96, $15-22$.

51 Bordel S., Mato R., Villaverde S. (2006) Modelling of the evolution with length of bubble size distributions in bubble columns, Chem. Eng. Sci. 61, 3663-3673.

52 Pérez-Garibay R., Martínez-Ramos E., Rubio J. (2012) Gas dispersion measurements in microbubble flotation systems, Miner. Eng. 26, 34-40. 